\title{
Relation between distal airspace size, bronchiolar attachments, and lung function
}

\author{
D Lamb, A McLean, M Gillooly, P M Warren, G A Gould, W MacNee
}

\begin{abstract}
Background-Smoking related fixed airway obstruction may be due to airway scarring and narrowing or decreased support due to loss of adjacent alveolar walls. In this study of resected specimens, preoperative pulmonary function was compared with results of a morphometric study of lung structure.

Methods-Morphometric measurements were made on 42 inflation fixed lung specimens as follows: airspace wall surface area per unit volume (AWUV) was measured on at least $251 \mathrm{~mm}^{2}$ histological fields from each specimen, expressed as a mean, and the mean of the lowest five measurements for each case (LF5). Minimum diameter, maximum diameter, diameter ratio (ellipticality), lumen area, and lumen circumference were measured on at least 16 non-respiratory bronchioles from each lung. Peribronchiolar alveolar support was measured as mean interalveolar attachment distance (IAAD). Measurements of pulmonary function included forced expiratory volume in one second $\left(\mathrm{FEV}_{1}\right)$ (absolute and $\%$ predicted values; $n=42$ ), slope of phase III (single breath nitrogen test; $\mathbf{n}=28$ ), closing volume (expressed as a percentage of vital capacity (CV/VC\%); $\mathrm{n}=28$ ).
\end{abstract}

Results-Bronchiolar size was not independently related to the tests of lung function used. Percentage predicted FEV 1 was related to mean IAAD, ellipticality, and mean AWUV. CV/VC\% showed significant relation with ellipticality, mean AWUV, and LF5 AWUV. Slope of phase III increased with increasing IAAD. Significant correlations were found between ellipticality and AWUV (mean and LF5), and between ellipticality and IAAD. Both IAAD and ellipticality were significantly increased in patients with abnormally low $\mathrm{FEV}_{1}$.

Conclusion-Destruction of airspace walls, particularly those attached to the peripheral bronchioles, is more influential in determining airflow limitation than bronchiolar size.

(Thorax 1993;48:1012-1017)

Chronic obstructive airways disease is characterised by a fixed airway obstruction that seems to be an acceleration of the normal age related decline in the forced expiratory volume in one second $\left(\mathrm{FEV}_{1}\right)$ seen in the nonsmoking population. ${ }^{1}$ Any study of the structural basis of this slowly progressive change must concentrate on the early stages of the disease process, rather than the end stage disease found at necropsy. The pattern of pathological changes in any end stage disease is a notoriously poor guide as to what the underlying pathogenetic processes are. Several studies have approached this by using surgically obtained lung specimens and have compared the structural changes found in the resected tissue with preoperative measurements of pulmonary function..$^{2-8}$ There are problems inherent in these investigations, however, including the non-random selection of cases. Cases with severe physiological abnormality who are unfit for operation are excluded. Most surgically obtained specimens are from patients with lung cancer and it is possible that the selection factors relating to the predisposition to smoking-related cancer are also related to chronic obstructive airways disease.

Studies based on surgically obtained lung tissue have several advantages, however, over those involving the use of necropsy material. A major advantage is that the interval between performing the pulmonary function tests and the surgical removal of the lung specimen is short, as surgery is usually performed within hours of completing these physiological tests. When using necropsy material in structure function studies, the interval between measuring pulmonary function and obtaining the lung specimen may be months or even years. The other major advantage of using surgical specimens is that it enables the study of structural changes in lungs with mild airflow limitation, whereas necropsy studies generally involve tissue from patients with end stage chronic obstructive airways disease. ${ }^{9-13}$

A major complicating factor common to all these studies is that smoking itself causes a range of histological and structural changes in the lung that may or may not in themselves be related to any functional deficit. It is necessary to take particular care that any apparent correlation between structural change and functional deficit is not part of a general family of relations present merely because they have a common link with smoking.

In structural terms there are few abnormalities that can provide fixed, non-reversible air- 
flow limitation. These are permanent narrowing of the airway lumen, or the potential functional changes in the behaviour of the airway associated with significant scarring of the wall, or the loss of external support by loss of adjacent alveolar walls as seen in certain forms of emphysema. In this study we have measured the size and shape of bronchioles, the distance between the alveolar attachments to bronchiolar walls, and assessed airspace size by measuring airspace wall surface area per unit volume of lung tissue (AWUV). We have compared the results of these measurements with those tests of pulmonary function associated with airflow limitation-namely, $\mathrm{FEV}_{1}, \%$ predicted $\mathrm{FEV}_{1}$, closing volume:vital capacity ratio (\%), and slope of phase III of the single breath nitrogen test.

\section{Methods}

PULMONARY FUNCTION TESTS

Pulmonary function was measured 48-72 hours before lobectomy or pneumonectomy performed as treatment for solitary tumours. The $\mathrm{FEV}_{1}$ was obtained for 42 patients (30 men, 12 women; two non-smokers, age range 46-74, mean age 60.5 years). The $\mathrm{FEV}_{1}$ was measured with a 7 litre dry spirometer (Vitalograph Ltd, UK). Percentage predicted values for the men were taken from Kory et $a l^{14}$ and those for women from Ferris et al. ${ }^{15}$ The closing volume vital capacity ratio (CV/VC\%) and the slope of phase III were calculated from the single breath nitrogen test. ${ }^{16}$ This test was performed on 28 of the patients with a wedge spirometer (Model 570, Medical Science Electronics Inc, St Louis, Missouri, USA) and a nitrogen analyser (Ohio Medical Products, PK Morgan Ltd, Chatham, UK).

Patients were divided into two subgroups on the basis of their $\mathrm{FEV}_{1}$ values. The FEV was considered normal if it was within 1.65 standard deviations of the predicted mean value for the patient's age and stature..$^{1417}$ Values for $\mathrm{FEV}_{1}$ below this level were considered abnormal.

\section{MORPHOMETRIC MEASUREMENTS}

Resected lungs or lobes were inflated by intrabronchial infusion of $10 \%$ buffered formalin at $25 \mathrm{~cm}$ water pressure and fixed for a minimum of 24 hours. They were then cut into $1 \mathrm{~cm}$ parasagittal slices, and six randomly selected blocks $(2 \mathrm{~cm} \times 2 \mathrm{~cm})$ were taken from each of the two lateral subpleural slices. Tissue blocks were then embedded in glycol methacrylate resin, cut at $3 \mu \mathrm{m}$, and stained with haematoxylin and eosin.

Minimum internal diameter, maximum internal diameter, ellipticality (ratio of maximum to minimum diameter), lumen area, and lumen circumference were measured in each bronchiole with a digitising tablet. The theoretical lumen area (TLA) was calculated by taking the lumen circumference, which frequently had an irregular outline, and using the formula, TLA = (lumen circumference) $)^{2} / 4 \pi$, to construct a figure representing the area of an airway lumen with the same measured circumference, but with a smoothed outline. Peribronchiolar support was measured in all 42 cases by counting the number of radial peribronchiolar attachments by the method of Linhartova et $a l .{ }^{18}$ To exclude variation in this figure relating to the varied size of individual bronchioles, the lumen circumference of each bronchiole was divided by the number of alveolar attachments to give the average distance between the attachments. This was expressed as the mean interalveolar attachment distance (IAAD).

Any measurement of airways in which the airways are cut at various angles leads to major problems owing to the size of the errors introduced by measurement of obliquely sectioned airways. To limit this we attempted to exclude from the study the most obliquely sectioned airways from each case. The maximum to minimum diameter ratios (ellipticality) for 10 cases were plotted as cumulative frequency distributions. All 10 distributions had a similar shape. The range of ellipticality was wide, but most airways had values at the lower end of the scale. Fewer than $30 \%$ of the airways occupied the remainder of the range. Therefore, by excluding the $30 \%$ most elliptical airways in each case, it is likely that the airways that were sectioned at extreme angles were omitted from the study. A mean number of 29 non-respiratory bronchioles (range 16-75) were measured from each case.

Airspace wall surface area per unit volume of lung tissue (AWUV) was measured with an IBAS image analysis system (Kontron Ltd, Watford, England) in all 42 specimens as previously described. ${ }^{18}$ The AWUV was measured in a minimum of 25 histological fields from each case, to attain a stable running mean. ${ }^{1920}$ It was expressed as a mean value for all the histological fields measured from each lung specimen, and as the mean of the lowest five fields measured (LF5 AWUV).

\section{STATISTICAL ANALYSIS}

The degree of correlation between the structural variables and the relations between the structural and functional variables were assessed with the Spearman correlation coefficient. $^{21}$ The structural differences between subgroups with normal and abnormal FEV were assessed by the Mann-Whitney $U$ test. $^{21}$

\section{Results}

Table 1 gives a summary of the mean values for the structural measurements and a list of the results of pulmonary function tests for each of the 42 patients.

RELATIONS BETWEEN STRUCTURE AND FUNCTION

\section{Bronchioles}

Bronchiolar minimum diameter was positively related to absolute $\mathrm{FEV}_{1}(r=0 \cdot 28$, $\mathrm{p}<0.05$ ), but was not related to any of the other functional variables. Neither measured 
Table 1 Mean values of structural variables and results of pulmonary function measurements for each patient

\begin{tabular}{|c|c|c|c|c|c|c|c|c|c|c|c|c|}
\hline Patient & $M I N$ & $M A X$ & $E L L I P T$ & $T L A$ & $A A$ & $L A A D$ & $A W U V$ & $L F 5$ & $F E V_{1} A$ & $F E V_{1} \%$ & $6 C V / V C$ & Phase III \\
\hline 1 & 0.61 & 0.98 & $1 \cdot 75$ & 1.36 & $22 \cdot 3$ & 201 & 16.89 & $9 \cdot 19$ & 2.55 & 85 & 39 & 2.95 \\
\hline 2 & 0.57 & 0.84 & 1.50 & 0.82 & 14.6 & 186 & 16.01 & $12 \cdot 89$ & 3.55 & 111 & - & - \\
\hline 3 & 0.57 & 0.73 & 1.30 & 0.52 & 16.4 & 145 & $17 \cdot 27$ & 13.94 & $2 \cdot 15$ & 83 & - & - \\
\hline 4 & 0.53 & 0.93 & 1.76 & $1 \cdot 34$ & $20 \cdot 3$ & 183 & $14 \cdot 36$ & $7 \cdot 23$ & 1.90 & 59 & 27 & - \\
\hline 5 & 0.49 & 0.63 & $1 \cdot 29$ & 0.47 & 16.7 & 141 & $20 \cdot 72$ & 16.39 & 3.05 & 92 & 16 & $2 \cdot 26$ \\
\hline 6 & 0.65 & 0.84 & 1.28 & 0.61 & $18 \cdot 2$ & 133 & 25.40 & 20.77 & 1.85 & 97 & - & - \\
\hline 7 & 0.53 & 0.77 & 1.50 & 0.74 & $15 \cdot 1$ & 208 & 19.08 & 12.97 & 2.65 & 70 & - & - \\
\hline 8 & 0.55 & 0.92 & $1 \cdot 70$ & 0.87 & $17 \cdot 8$ & 180 & $10 \cdot 15$ & $4 \cdot 11$ & $2 \cdot 10$ & 66 & 36 & $2 \cdot 21$ \\
\hline 9 & 0.78 & $1 \cdot 14$ & 1.46 & 1.38 & 20.8 & 172 & 14.57 & 10.79 & 1.75 & 88 & 24 & - \\
\hline 10 & 0.57 & 0.86 & 1.52 & 0.92 & 19.6 & 172 & 23.04 & 15.84 & 3.25 & 88 & - & - \\
\hline 11 & 0.46 & 0.68 & 1.53 & 0.47 & 16.8 & 160 & 8.78 & 3.85 & $1 \cdot 40$ & 74 & - & - \\
\hline 12 & 0.46 & 0.66 & 1.46 & 0.92 & 18.9 & 167 & $21 \cdot 18$ & $17 \cdot 37$ & $2 \cdot 10$ & 68 & 20 & 3.82 \\
\hline 13 & 0.53 & 0.71 & 1.36 & 0.54 & $18 \cdot 1$ & 168 & $24 \cdot 74$ & 21.26 & $2 \cdot 55$ & 75 & 20 & 1.71 \\
\hline 14 & 0.50 & 0.66 & $1 \cdot 34$ & 0.42 & $17 \cdot 1$ & 134 & 20.52 & $17 \cdot 40$ & 1.80 & 82 & - & - \\
\hline 15 & 0.48 & 0.71 & 1.50 & 0.83 & $17 \cdot 4$ & 161 & 15.87 & 9.73 & 2.90 & 94 & 22 & $3 \cdot 38$ \\
\hline 16 & 0.45 & 0.67 & 1.53 & 0.74 & 14.0 & 155 & 22.58 & 18.72 & $2 \cdot 10$ & 116 & 29 & 0.38 \\
\hline 17 & 0.60 & 0.92 & 1.56 & 1.56 & $22 \cdot 0$ & 136 & 18.70 & 8.41 & 3.45 & 108 & 26 & $1 \cdot 41$ \\
\hline 18 & 0.56 & 0.76 & 1.40 & 0.83 & $18 \cdot 3$ & 151 & 16.81 & $13 \cdot 82$ & 3.75 & 121 & 26 & 0.84 \\
\hline 19 & 0.55 & 0.90 & 1.72 & $1 \cdot 25$ & 18.0 & 189 & 14.42 & 6.55 & $2 \cdot 10$ & 62 & 22 & 4.65 \\
\hline 20 & 0.56 & 0.90 & 1.77 & 1.23 & 14.9 & 244 & 15.77 & 9.00 & 1.40 & 47 & 48 & $4 \cdot 41$ \\
\hline 21 & 0.42 & 0.63 & 1.57 & 0.67 & 14.6 & 170 & 16.58 & $12 \cdot 10$ & 1.65 & 52 & - & - \\
\hline 22 & 0.59 & 0.82 & 1.44 & 0.65 & $12 \cdot 2$ & 198 & $19 \cdot 47$ & $16 \cdot 21$ & 1.35 & 47 & 30 & 4.82 \\
\hline 23 & 0.41 & 0.64 & 1.62 & 0.56 & $16 \cdot 0$ & 166 & 21.97 & $18 \cdot 10$ & $3 \cdot 20$ & 110 & 17 & 1.43 \\
\hline 24 & 0.52 & 0.74 & 1.48 & 0.58 & 19.4 & 163 & 20.40 & $16 \cdot 21$ & 2.05 & 79 & 17 & 3.04 \\
\hline 25 & 0.75 & 0.97 & 1.31 & 1.04 & 19.4 & 177 & 20.77 & 15.93 & $2 \cdot 15$ & 74 & 16 & $4 \cdot 83$ \\
\hline 26 & 0.43 & 0.68 & 1.60 & 0.62 & 16.0 & 175 & $15 \cdot 50$ & 11.83 & $1 \cdot 40$ & 67 & 22 & 5.33 \\
\hline 27 & 0.50 & 0.80 & 1.69 & 0.89 & $15 \cdot 3$ & 176 & $17 \cdot 73$ & 13.04 & 2.55 & 98 & 26 & 4.93 \\
\hline 28 & 0.52 & 0.77 & 1.50 & 0.82 & $14 \cdot 2$ & 206 & 19.52 & 13.07 & 1.55 & 67 & 26 & 5.08 \\
\hline 29 & 0.72 & 1.00 & 1.40 & $1 \cdot 20$ & 17.6 & 185 & 20.59 & 9.93 & 2.65 & 83 & 10 & - \\
\hline 30 & 0.38 & 0.56 & 1.47 & 0.32 & 13.0 & 143 & 16.78 & 12.84 & 1.75 & 52 & 21 & $6 \cdot 40$ \\
\hline 31 & 0.57 & 0.85 & 1.53 & 0.79 & 16.8 & 191 & 17.94 & 14.09 & 1.95 & 72 & - & - \\
\hline 32 & 0.45 & 0.68 & 1.49 & 0.61 & $20 \cdot 6$ & 124 & 17.94 & 12.92 & 2.00 & 90 & - & - \\
\hline 33 & 0.72 & 0.98 & 1.36 & 0.72 & $17 \cdot 4$ & 177 & 16.64 & $13 \cdot 29$ & $2 \cdot 70$ & 87 & 5 & 1.83 \\
\hline 34 & 0.52 & 0.72 & 1.36 & 0.46 & 14.5 & 190 & $18 \cdot 77$ & 14.01 & $2 \cdot 45$ & 84 & 13 & $3 \cdot 14$ \\
\hline 35 & 0.60 & 0.93 & 1.55 & 1.06 & 15.0 & 200 & 19.57 & 15.98 & 1.50 & 54 & 12 & 3.98 \\
\hline 36 & 0.86 & $1 \cdot 16$ & 1.41 & 1.40 & 22.0 & 174 & $19 \cdot 20$ & $14 \cdot 75$ & $2 \cdot 60$ & 90 & 20 & 3.96 \\
\hline 37 & 0.49 & 0.83 & 1.72 & 0.62 & 16.6 & 150 & 22.00 & 13.78 & $1 \cdot 70$ & 81 & - & - \\
\hline 38 & 0.61 & 0.87 & 1.48 & 0.78 & 22.0 & 154 & 18.04 & $12 \cdot 35$ & $3 \cdot 10$ & 107 & 27 & 0.40 \\
\hline 39 & 0.36 & 0.64 & 1.96 & 0.48 & 11.9 & 225 & $14 \cdot 29$ & 2.01 & 1.65 & 53 & - & - \\
\hline 40 & 0.63 & 0.89 & $1 \cdot 40$ & 0.94 & $17 \cdot 5$ & 163 & 17.75 & 14.89 & 1.65 & 72 & 25 & 4.92 \\
\hline 41 & 0.53 & 0.78 & $1 \cdot 48$ & 0.65 & $19 \cdot 2$ & 148 & 17.91 & $11 \cdot 28$ & $2 \cdot 45$ & 123 & - & - \\
\hline 42 & 0.37 & 0.60 & 1.68 & 0.39 & 14.9 & 156 & $17 \cdot 32$ & 9.02 & 1.00 & 53 & - & - \\
\hline
\end{tabular}

MIN-bronchiolar minimum diameter ( $\mathrm{mm}$ ); MAX-bronchiolar maximum diameter (mm); ELLIPT-ellipticality (ratio of MAX:MIN); TLA - theoretical lumen area (mm); AA-mean number of alveolar attachments/bronchiole; IAAD -interalveolar attachment distance $(\mu \mathrm{m}) ; A W U V$-airspace wall surface area per unit volume of lung tissue $\left(\mathrm{mm}^{2} / \mathrm{mm}^{3}\right)$; LF5-mean of the 5 lowest AWUV values $\left(\mathrm{mm}^{2} / \mathrm{mm}^{3}\right)$; FEV $\mathrm{A}$-absolute measurement of forced expiratory volume in one second (1); FEV $\%$-predicted $\mathrm{FEV}_{1}$ for a given age and stature (\%); CV/VC-ratio of closing volume to vital capacity (\%); Phase III-slope of phase III of the single breath nitrogen washout curve.

lumen area nor theoretical lumen area showed significant relations with any of the functional variables.

\section{Alveolar support to bronchioles}

The mean distance between the alveolar attachments to the bronchioles (IAAD) showed a significant negative relation with the $\%$ predicted $\mathrm{FEV}_{1}$ (fig 1), and a positive relation with the slope of phase III (table 2).

Figure 1 Percentage predicted FEV 1 plotted against mean LAAD showing a significant relation between these variables $(r=-0.48$, $p=0.001)$. This indicates that a fall in $F E V$, is associated with a loss of the radial attachments to peripheral bronchioles.

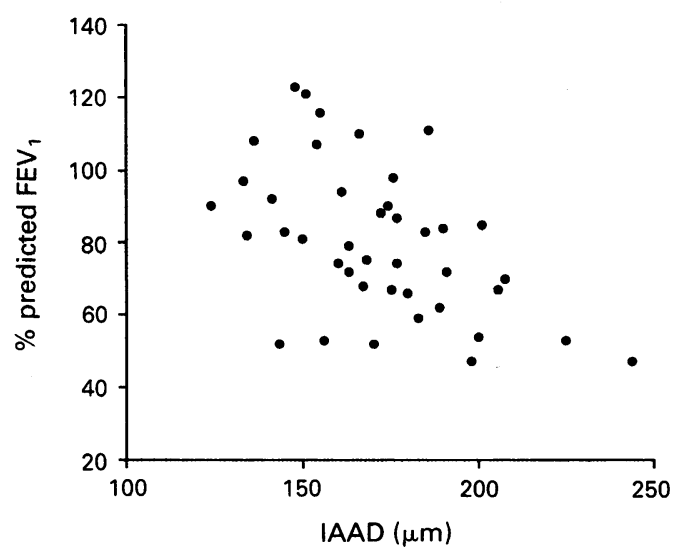

Bronchiolar shape

Ellipticality correlated with \% predicted $\mathrm{FEV}_{1}$ and CV/VC\% (table 2).

Assessment of distal airspace size

Mean AWUV was related to \% predicted $\mathrm{FEV}_{1}$ and to $\mathrm{CV} / \mathrm{VC} \%$. The relation between LF5 AWUV and \% predicted FEV 1 did not reach significance $(p=0.06)$, but there was a relation between LF5 AWUV and CV/VC\% (table 2).

RELATION BETWEEN STRUCTURAL VARIABLES

There was a weak relation between mean AWUV and IAAD (fig 2). It is clear from fig 2 that this relation was weakened by the presence of two outliers in whom the alveolar support for bronchioli was maintained despite the apparent generalised increase in airspace size indicated by low mean AWUV values. This was confirmed by re-examination of the histological sections.

It became obvious in the course of making these measurements that the shape of the air- ? ways varied from case to case, and that in some cases the airways showed a noticeably more elliptical profile, even after the exclusion of the $30 \%$ most elliptical airways from 
Table 2 Correlation coefficients for the relations between structural and functional variables

\begin{tabular}{|c|c|c|c|c|}
\hline & $F E V_{1}$ & $\%$ Predicted FEV & $C V / V C \%$ & Slope of phase III \\
\hline $\begin{array}{l}\text { IAAD } \\
\text { Ellipticality } \\
\text { Mean AWUV } \\
\text { LF5 AWUV }\end{array}$ & $\begin{array}{l}r=-0 \cdot 15, \mathrm{NS} \\
r=-0 \cdot 26, \mathrm{NS} \\
r=0 \cdot 22, \mathrm{NS} \\
r=0 \cdot 14, \mathrm{NS}\end{array}$ & $\begin{array}{l}r=-0.48, \mathrm{p}=0.001 \\
r=-0.31, \mathrm{p}<0.05 \\
r=0.28, \mathrm{p}<0.05 \\
r=0.24, \mathrm{NS}\end{array}$ & $\begin{array}{l}\mathrm{r}=0.10, \mathrm{NS} \\
r=0.60, \mathrm{p}<0.001 \\
r=-0.42, \mathrm{p}=0.01 \\
r=-0.42, \mathrm{p}=0.01\end{array}$ & $\begin{array}{l}r=0.41, \mathrm{p}<0.05 \\
r=0.08, \mathrm{NS} \\
r=-0 \cdot 26, \mathrm{NS} \\
r=-0 \cdot 18, \mathrm{NS}\end{array}$ \\
\hline
\end{tabular}

NS-not significant. For other definitions see footnote to table 1 .

each case. Ellipticality was related to airspace size (LF5 AWUV $r=-0.60, p<0.001$; mean AWUV $r=-0.44, \mathrm{p}<0.01$ ) and to the external support to the bronchiolar walls, expressed as IAAD $(r=0.39, \mathrm{p}<0.01)$.

\section{STRUCTURAL DIFFERENCES BETWEEN SUBGROUPS WITH NORMAL AND ABNORMAL $\mathrm{FEV}_{1}$}

When the cases were subdivided into groups with normal and abnormal $\mathrm{FEV}_{1}$ there were no differences between these subgroups in any of the measurements of airway size. The abnormal group, however, had significantly higher values of IAAD $(p<0.01)$ and bronchiolar ellipticality $(p<0.05)$.

\section{Discussion}

The work of Hogg et $a^{22}$ was fundamental to the concept that the increased resistance to airflow resided within smaller as opposed to larger airways in subjects with chronic airflow limitation. The functional contribution of small airway narrowing has been questioned, however, by a number of investigators who have failed to find differences in small airway calibre between emphysematous and nonemphysematous lungs, ${ }^{2423-25}$ or between smokers and non-smokers. ${ }^{24}$ Bosken et $a l$ have reported that in pooled data from groups of age matched patients with and without abnormal $\mathrm{FEV}_{1}$ an increased proportion of smaller airways was found in the group with airway obstruction.

We have failed to identify any relation between measurements of bronchiolar sizenamely diameter, cross sectional area, or derived theoretical lumen area-and \% predicted $\mathrm{FEV}_{1}$; or between these measurements of airway size in groups of patients with nor-

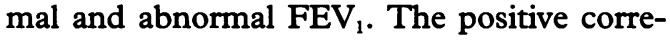
lation between minimum diameter and

Figure 2 Relation between mean $L A A D$ and mean $A W U V$

$(r=-0 \cdot 26, p=0.05)$ weakened by the presence of two outliers. These subjects retained alveolar attachments (low LAAD values), whereas the general enlargement of airspaces in these lungs was indicated by low mean AWUV values.

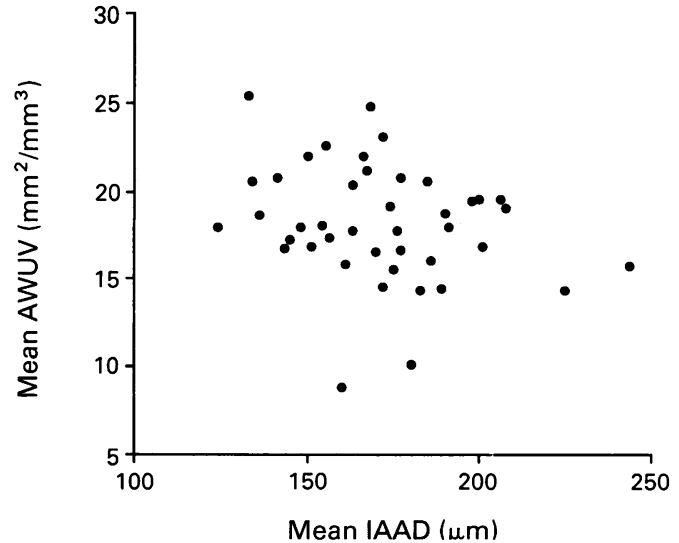

absolute $\mathrm{FEV}_{1}$ merely reflects the relation between lung dimensions and stature. The reason for the differences between our results and the findings of Bosken and colleagues is uncertain. There are differences between these two studies in the number of airways studied (Bosken et al used a minimum of five per patient, whereas in our study a minimum of 16 and a mean of 29 per patient were measured). Furthermore, we have studied our data on a case by case basis, whereas Bosken et al pooled the data from their groups of patients with normal and abnormal $\mathrm{FEV}_{1}$. Bosken's group did not investigate the effect of airspace size or bronchiolar attachments on FEV $_{1}$.

The work of Anderson and Foraker, ${ }^{26}$ and Linhartova and coworkers ${ }^{182728}$ has stressed the importance of peribronchiolar alveolar attachments in maintaining airway shape. These authors suggested that airway distortion might be related to airflow limitation. Petty and coworkers ${ }^{11}$ showed a relation between the number of attachments per bronchiole and the $\mathrm{FEV}_{1}$ in a group of lungs from patients with chronic obstructive airways disease coming to necropsy. Nagai et $a l^{13}$ showed a relation between the distance between alveolar attachments and the slope of phase III, but attachment distance was not related to changes in $\mathrm{FEV}_{1}$. In the present study we have identified a strong negative correlation between IAAD and \% predicted $\mathrm{FEV}_{1}$. Similarly, when the cases were divided into those with normal and abnormal $\mathrm{FEV}_{1}$, a significant difference was identified between the IAAD values in the two groups. The relation between IAAD and $\mathrm{FEV}_{1}$ reported here seems stronger than that reported by Petty and colleagues, ${ }^{11}$ but they measured the total number of attachments per airway wall without any compensation for the variation in airway size, whereas we have measured the mean distance between attachments.

The relation between IAAD, measured in association with the most peripheral bronchioles, and $\mathrm{FEV}_{1}$ may seem surprising, as $\mathrm{FEV}_{1}$ has been considered to be a measure of large airway function. Several studies have reported, however, that the major site of increased resistance to airflow in chronic obstructive airways disease is the peripheral airways, and therefore the $\mathrm{FEV}_{1}$ should reflect abnormalities of peripheral airways. ${ }^{22} 2931$ Although we have measured IAAD associated with the smaller peripheral bronchioles, the effect of any lack of support associated with an increase in IAAD is not confined to such airways. It is probable that all the bronchioles and the smaller, peripheral bronchi in which 
the cartilage plates are widely separated, depend on support from adjacent alveolar walls for their functional integrity. It might be argued that a measure of the largest IAAD (the largest gap between alveolar attachments supporting a bronchiole) would be more important than mean IAAD. Such large gaps might provide areas of particular susceptibility to premature closure during expiration. We have compared the frequency distribution of individual IAAD measurements with the mean values, and found that the upper $10 \%$ of such measurements were so closely related to the mean value that it was impossible to separate the individual contributions of these two sets of measurements in relation to lung function (Lamb, Stewart, and McLean, unpublished observations).

Ellipticality is an expression of airway shape, and as such is not a fixed or absolute measurement, and is likely to change with the respiratory cycle in life, or with the method of fixation in a pathological specimen. In our material, ellipticality seems to reflect both a lack of local support by loss of alveolar walls adjacent to bronchioli and also a decrease in the more general support identified as a fall in the mean AWUV value. Despite the relation between mean AWUV and IAAD, ellipticality and its functional effects are influenced by apparently independent contributions of these two structural changes. The presence of outliers in fig 2 supports this concept.

We have confirmed the positive relation between distance between alveolar attachments and the slope of phase III previously reported by Nagai et al. ${ }^{13}$ Thus loss of attachments leads to increased lack of homogeneity in the distribution of ventilation in the lungs. ${ }^{16}$ We did not find a direct relation between $\mathrm{CV} / \mathrm{VC} \%$ and IAAD as might be predicted on the basis that loss of attachments would allow airway closure to occur at a higher lung volume. The negative relation between CV/VC\% and both ellipticality and measures of AWUV (mean and LF5) can, however, be explained on the basis that increased ellipticality and decreased AWUV reflect a reduction in general support for the airways, thus allowing premature collapse.

Despite the interest in relating macroscopic emphysema to loss of function in end stage chronic obstructive airways disease, ${ }^{9-13}$ there has been surprisingly little interest in the measurement of airspace size and function in mild or early chronic obstructive airways disease. ${ }^{4}$ We have shown that an increase in airspace size, with a corresponding decrease in mean AWUV, does show a relation to impaired pulmonary function. The loss or retention of those airspace walls supporting bronchioli seem to be more functionally influential, however, than changes in mean AWUV.

This concept that peribronchiolar attachments are fundamental to bronchiolar shape and function is not new, and in particular the work of Linhartova and colleagues clearly shows this. ${ }^{28}$ Our study extends the concept. Our results imply that bronchiolar size is less important than the destruction of distal airspace walls in determining airflow limitation. We have not investigated here the amount of inflammation and scarring in the bronchioles, which others have measured semiquantitatively and found to relate to loss of pulmonary function. ${ }^{45-113233}$ Such inflammatory changes in the bronchioles may not affect pulmonary function directly, but may reflect the pathogenesis of the loss of radial attachments described in this paper.

This study was supported by the Norman Salvesen Emphysema Research Fund.

1 Cotes JE. Lung function: assessment and application in medicine. 4th ed. Oxford: Blackwell, 1979:361-87.

2 Cosio MG, Hale KA, Niewoehner DE. Morphological and morphometric effects of prolonged cigarette smoking on the small airways. Am Rev Respir Dis 1980 122:265-71.

3 Wright JL, Lawson LM, Pare PD, Wiggs BJ, Kennedy S, Hogg JC. Morphology of peripheral airways in current and ex-smokers. Am Rev Respir Dis 1983;127:474-7.

4 Saetta M, Ghezzo H, Kim WD, King M, Angus GE, Wang NS, Cosio MG. Loss of alveolar attachments in smokers. A morphometric correlate of lung function impairment. Am Rev Respir Dis 1985;132:894-900.

5 Wright JL, Hobson JE, Wiggs B, Pare PD, Hogg JC. Airway inflammation and peribronchiolar attachment in the lungs of nonsmokers, current and exsmokers. Lung 1988;166:277-86.

6 Matsuba K, Wright JL, Wiggs BR, Pare PD, Hogg JC The changes in airways structure associated with reduced forced expiratory volume in one second. Eur Respir 7 1989;2:834-9.

7 Bosken CH, Wiggs BR, Pare PD, Hogg JC. Small airway dimensions in smokers with obstruction to airflow. $A$ Rev Respir Dis 1990;142:563-70.

8 Willems LNA, Kramps JA, Stijen T, Sterk PJ, Weening J Dijkman JH. Relation between small airways diseas and parenchymal destruction in surgical lung specimens. Thorax 1990;45:89-94.

9 Mitchell RS, Stanford RE, Johnson JM, Silvers GW, Dart G, George MS. The morphologic features of the bronchi, bronchioles and alveoli in chronic airwa obstruction: A clinicopathologic study. Am Rev Respir Dis 1976;114:137-45.

10 Nagai A, West WW, Paul $\pi$, Thurlbeck WM. The National Institutes of Health intermittent positivepressure breathing trial: pathology studies. I. Interrelationship between morphologic lesions. Am Re Respir Dis 1985;132:937-45.

11 Petty TL, Silvers GW, Stanford RE. Radical traction and small airways disease in excised human lungs. $\mathrm{Am} \mathrm{Rev}$ Respir Dis 1986;133:132-5.

12 West WW, Nagai A, Hodgkin JE, Thurlbeck WM. The National Institutes of Health intermittent positivepressure breathing trial: pathology studies. III. The diagnosis of emphysema. Am Rev Respir Dis 1987;135: 123-9.

13 Nagai A, Yamawaki I, Takizawa T, Thurlbeck WM. Alveolar attachments in emphysema of human lungs. Am Rev Respir Dis 1991;144:888-91.

14 Kory RC, Callahan R, Boren HG, Syner JC. The veterans administration-army co-operative study of pulmonary function. Am F Med 1961;30:243-58.

15 Ferris BG, Anderson DO, Zickmantel R. Prediction values for screening tests of pulmonary function. $\mathrm{Am}$ Rev Respir Dis 1965;91:252-61.

16 Buist AS, Ross BB. Quantitative analysis of the alveolar plateau in the diagnosis of early airway obstruction. $\mathrm{Am}$ Rev Respir Dis 1973;108:1078-87.

17 Quanjer $\mathrm{Ph} \mathrm{H}$. Standardized lung function testing. Working Party Report for the European Commission for Coal and Steel. Bull Eur Physiopathol Respir 1983; 19:(Suppl 5):7-10.

18 Linhartova A Anderson AE, Foraker AG. Radical traction and bronchiolar obstruction in pulmonary emphysema. Observed and theoretical aspects. Arch Pathol 1971;92:384-91

19 McLean A, Warren PM, Gillooly M, MacNee W, Lamb D. Microscopic and macroscopic measurements of D. Thorax 1992;47:144-9.

20 Aherne WA, Dunnill MS. Morphometry. London: Edward Arnold, 1982: 24-8.

21 Siegel S, Castellan NJ. Nonparametric statistics for the behavioural sciences. 2nd ed. New York: McGraw-Hill, 1988. 
22 Hogg JC, Macklem PT, Thurlbeck WM. Site and nature of airway obstruction in chronic obstructive lung disease. N Engl f Med 1968;278:1355-60.

23 Matsuba $K$, Thurlbeck WM. The number and dimension of small airways in nonemphysematous lungs. Am Rev Respir Dis 1971;104:516-28.

24 Matsuba K, Thurlbeck WM. The number and dimensions of small airways in emphysematous lungs. Am $\mathcal{F}$ Pathol 1972;67:265-76.

25 Petty TL, Silvers GW, Stanford RE. Functional correlations with mild and moderate emphysema in excised human lungs. Am Rev Respir Dis 1981;124:700-4.

26 Anderson AE, Foraker AG. Relative dimensions of bronchioles and parenchymal spaces in lungs from normal subjects and emphysematous patients. Am $\mathcal{F}$ Med 1962; 32:218-26.

27 Linhartova A, Anderson AE, Foraker AG. Nonrespiratory bronchiolar deformities. Arch Pathol 1973;95:45-8.

28 Linhartova A, Anderson AE, Foraker AG. Affixment arrangements of peribronchiolar alveoli in normal and emphysematous lungs. Arch Pathol Lab Med 1982;106: 499-502.

29 Silvers GW, Maisel JC, Petty TL, Mitchell RS, Filley GF. Central airways resistance in excised emphysematous lungs. Chest 1972;61:603-12.

30 Zamel N, Hogg JC, Gelb A. Mechanisms of maximal expiratory flow limitation in clinically unsuspected emphysema and obstruction of the peripheral airways. Am Rev Respir Dis 1976;113:337-45.

31 Thurlbeck WM. Pathology of chronic airflow obstruction. In: Cherniak NS, ed. Chronic obstructive pulmonary disease. Philadelphia: WB Saunders, 1991:3-20.

32 Cosio MG, Ghezzo $H$, Hogg JC, Corbin R, Loveland $M$, Dosman J, Macklem PT. The relations between structural changes in small airways and pulmonary function tests. $N$ Engl F Med 1978;298:1277-81.

33 Berend N, Thurlbeck WM. Correlation of maximum expiratory flow with small airway dimensions and pathology. Fournal Applied Physiology: Respiratory Environmental and Exercise Physiology 1982;52:346-51.

\section{On sepsis and defining words}

"Sepsis" and its adjectival form "septic" come from the Greek "sepein"-to make putrid. The relationship between sepsis, putrefaction, and smell is evident in such familiar terms as "antiseptic" (anything preventing the toxic action of microorganisms) and "septic tank" (where anaerobic bacteria putrefy and decompose waste). Medically "sepsis" is linked to its roots in bacterial putrefaction. The natural progression of smelly, festering wounds was described in antiquity by Hippocrates. In 1712 English physicians, ignorant of bacterial action, employed the term "antiseptick" for compounds that retarded putrefaction of corpses. By the mid 18th century "antiseptic" entered into lay vocabulary. This distinction between "septic" and "antiseptic" chemicals was the foundation for Lister, who developed the revolutionary concept of antiseptic surgery a century later.

German pathologists described late stage infection-when putrefaction set in-as "sepsis." By the early 1900s "sepsis" and its more common counterpart "septicaemia" were diagnostic terms describing patients who presumably absorbed poisons emanating from foul smelling foci.

Smell was an important factor in the diagnostic armamentarium of physicians at the turn of the century. Thus the most common use of sepsis-“puerperal sepsis"-described infections where lochial odour was diagnostic.

As a result of the large numbers of surgically treated traumatic wounds in the first world war "sepsis" and "septicaemia" gained greater popularity. With the identification of specific bacteria "septicaemia" became associated with systemic manifestations of staphylococcal and streptococcal infections.

The discovery of antibiotics became linked with a host of virtually indistinguishable terms to describe systemic infection such as bacteraemia, septicaemia, toxaemia, pyaemia, and sapraemia (same Greek derivation as sepsis). Between the world wars "sepsis" was relegated to describing local, rather than systemic, infections and the term was nearly abandoned.

The second world war saw widespread use of antibiotics and heightened interest in the treatment of shock, which researchers classified as cardiogenic, haemorrhagic, anaphylactic, or septic. In the Darwinian struggle for semantic survival "sepsis" possessed distinct advantages-its easy transition from noun to adjective and the smooth alliteration of "septic shock" describing bacterially induced hypoperfusion (imagine "pyaemic shock"). Pyaemia, sapraemia, and toxaemia all fell into disuse by the 1950s.

One important reason for defining sepsis and related hard to define terms is to provide researchers with workable definitions to evaluate new treatments for serious infections. However, we will not soon read the last word on defining words. As linguist Jacques Barzun has aptly noted: "(word) usage is the most elusive of realities and defining is one of the most difficult acts of thought."

"Sepsis" connotes a diagnosis and severity of illness better than terms it has outlasted over the past century. The history of "sepsis" is one of the amorphousness of words, our perceptions of them, the phenomena they describe, and our attempts to control them. Where science and semantics intersect, the story of "sepsis" reinforces TS Eliot's admonition that ultimately the only wisdom we can hope to acquire is the wisdom of humility.

CORY FRANKLIN 